chronic disease patients may be attributed to the value of treatment by patients and their family, and also due to the existence of a multidisciplinary team at the reference center. These data might be useful for public health policy making in other countries.

\section{PP046 Screening In Women Vaccinated Against Human Papillomavirus: Governing Innovation}

\section{AUTHORS:}

Paolo Giorgi Rossi (paolo.giorgirossi@ausl.re.it), Francesca Carozzi, Antonio Federici, Guglielmo Ronco, Marco Zappa, Silvia Franceschi

\section{INTRODUCTION:}

In Italy, the cohorts of women who were offered Human papillomavirus (HPV) vaccination in 2007/08 will reach the age for cervical cancer (CC) screening from 2017. According to the National Prevention Plan 2014-18, HPV-based screening must be implemented for women $\geq 30$ years old, following the Italian Health Technology Assessment (HTA) report recommendations (1). The simultaneous shift from cytology-based screening to HPV test-based screening gives the opportunity for unprecedented reorganisation of CC prevention.

\section{METHODS:}

The National Screening Monitoring Centre and the Italian Group for Cervical Screening, following a commitment by the Italian the Ministry of Health $(\mathrm{MoH})$, identified the consensus conference as the most suitable method for addressing this topic. The objective was defining the best screening methods in girls vaccinated against HPV and the knowledge needs for defining evidence-based screening strategies. During the consensus celebration (24 November 2015) a jury made recommendations about questions and proposals formulated by a panel of experts representative of Italian scientific societies involved in CC prevention and based on systematic reviews (2).

\section{RESULTS:}

The jury considered changing the screening protocols for girls vaccinated in their 12th year as appropriate. Tailored screening protocols based on vaccination status could be replaced by "one size fits all" protocols only when a herd immunity effect has been reached. Vaccinated women should start screening at age 30 , instead of 25 , with the HPV test. Furthermore, there is a strong rationale for applying longer intervals for re-screening HPV negative women than the currently recommended 5 years, but research is needed to determine the optimal screening time points. For nonvaccinated women and for women vaccinated in their 15 th year or later, the current protocol should be kept.

\section{CONCLUSIONS:}

As further action, in 2016 the Ministry of Health funded a Health Technology Assessment program of the new screening protocol proposed by the consensus conference and a cohort study for determining a safe interval in vaccinated women.

\section{REFERENCES:}

1. Ronco G, Biggeri A, Confortini M, et al. Health technology assessment report: HPV DNA based primary screening for cervical cancer precursors. Epidemiol Prev. 2012;36(3-4 Suppl 1):e1-72.

2. Giorgi Rossi P, Carozzi F, Federici A, et al. Italian Screening in HPV vaccinated girls Consensus Conference group. Cervical cancer screening in women vaccinated against human papillomavirus infection: Recommendations from a consensus conference. Prev Med. 2016; 25. pii: S0091-7435(16)30375-9.

\section{PP047 Intravenous Iron Sucrose Therapy In Real-World Anemic Patients}

\section{AUTHORS:}

Armando Alcobia, Ana Soares, Maria Francisca Delerue, Hélder Mansinho, Hélder Pereira, Jorge Félix 